\title{
BIBECHANA
}

A Multidisciplinary Journal of Science, Technology and Mathematics ISSN 2091-0762 (Print), 2382-5340 (Online)

Journal homepage: http://nepjol.info/index.php/BIBECHANA

Publisher: Research Council of Science and Technology, Biratnagar, Nepal

\section{Temperature dependence of entropy of mixing of liquid alkali alloys}

\author{
B. K. Singh ${ }^{1 *}$, Sudhir Singh ${ }^{2}$, Golak Kumar Mandal ${ }^{1}$, Dhiraj Kumar Jha ${ }^{1}$ \\ ${ }^{1}$ University Department of Physics, T.M. Bhagalpur University, Bhagalpur \\ ${ }^{2}$ Department of Physics, R. D. College Sheikhpura, T.M. Bhag. Univ., Bhagalpur \\ "E-mail : bijay.k.singh@gmail.com
}

Article history: Received 21 May, 2016; Accepted 3 August, 2016

DOI: http://dx.doi.org/10.3126/bibechana.v14i0.15410

This work is licensed under the Creative Commons CC BY-NC License.

https://creativecommons.org/licenses/by-nc/4.0/

(c) (1) (8)

\begin{abstract}
A semi-empirical approach has been considered to study the temperature dependence of entropy of mixing, ( $s^{\mathrm{M}}$ ), for various alkai-alkali alloys using hard-sphere model. The most important physical parameters occurring here is the hard-sphere diameter $(\sigma)$ and the packing fraction $(\eta)$. For pure liquid metals, this is usually determined empirically from the observed entropy as a function of temperature which in turn are utilised to compute $\mathrm{S}^{\mathrm{M}}$ for $\mathrm{Na}-\mathrm{K}, \mathrm{K}-\mathrm{Rb}, \mathrm{Na}-\mathrm{Rb}, \mathrm{NaCs}, \mathrm{Rb}-\mathrm{Cs}$ and $\mathrm{K}-\mathrm{Cs}$ alloys as a function of concentration at five different temperature ranging from $400^{\circ} \mathrm{K}-800^{\circ} \mathrm{K}$. The study reveals that entropy of mixing for $\mathrm{Na}-\mathrm{K}, \mathrm{Na}-\mathrm{Rb}$ and $\mathrm{K}-\mathrm{Rb}$ systems decreases with increasing temperature. But the result for Cs-based alloys exhibit a mixed behaviour.
\end{abstract}

Keywords: Alkali alloys; Semi-empirical approach; Entropy; Helmholtz free energy, Boltzmann Constant; Packing fraction.

\section{Introduction}

Though enormous experimental data exist on entropy of pure liquid metals and alloys [1], the theoretical works lag behind. Recently the hard-sphere (HS) model has been widely used to remedy this lack. The theoretical study of the entropy of mixing is of current interest to unlock the secrets of the structure of liquid alloys on the basis of experimental observations. The most important and basic ingredients are the hard sphere diameter $(\sigma)$ and the packing fraction $(\eta)$. Several workers [2-5] have computed the HS parameters by minimising the free energy of the system through first principle estimation. In the present work, a semi-empirical technique, without undergoing a rigorous first principle calculation attempt has 
been made to determine the HS parameters from the observed entropy of pure liquid metals[6], which in turn are utilised to compute the entropy of mixing for $\mathrm{Na}-\mathrm{K}$, Na-Rb, K-Rb, Na-Cs, Rb-Cs, and K-Cs alloys [7] as a function of concentration and temperature. These systems are preferred as their densities as a function of composition are experimentally available [8] and also there are typical representation of simple system where the sizes of constituent atoms differ from a factor of 1 to 3. Out of these, Cs-based binary molten of alloys are of particular interest for both theoretical [9-12] and experimental workers [1315].

\section{Theory}

We consider a simple binary liquid alloy with components of atomic concentration $\mathrm{C}_{1}$ and $\mathrm{C}_{2}$ comprising $\mathrm{C}_{1} \mathrm{~N}$ hard spheres with diameter $\sigma_{1}$ of species 1 and $\mathrm{C}_{2 \mathrm{~N}}$ with diameter $\sigma_{2}$ of species 2 . Following Umar et. al., the expression for the entropy of hard sphere mixture can be expressed as

$$
\mathrm{S}=\mathrm{S}_{\mathrm{gas}}+\mathrm{S}_{\mathrm{c}}+\mathrm{S}_{\eta}+\mathrm{S}_{\sigma}
$$

where $S_{\text {gas }}$ is the ideal gas entropy, $S_{c}$ represents the ideal entropy of mixing, $S_{\eta}$ corresponds to the packing density $\eta$ and $S_{\sigma}$ is the entropy contribution due to mismatch of the hard sphere diameters $\sigma_{1}$ and $\sigma_{2}$. Explicit expression for the various contributions are

$$
\begin{aligned}
& \frac{S_{g a s}}{K_{B}}=\frac{5}{2}+\lambda_{n}\left\{\Omega\left(\frac{m_{1}^{c_{1}} m_{2}^{c_{2}} K_{B} T}{2 \pi \hbar^{2}}\right)^{3 / 2}\right\} \\
& \frac{S_{c}}{K_{B}}=-\left(C_{1} \ln C_{1}+C_{2} \ln C_{2}\right) \\
& \frac{S_{\eta}}{K_{B}}=-(\alpha-1)(\alpha+\beta) \\
& \frac{S_{c}}{K_{B}}=A C_{1} C_{2}+\left(\sigma_{2}-\sigma_{2}\right)^{2}
\end{aligned}
$$

The expressions used for $S_{\eta}$ and $S_{\sigma}$ which are derived by Umar et. al.[16] from the Helmholtz free energy formulae of Mansoori et. al.]17], the latter work itself providing an accurate analytical fit to the computer Simulation data.

Here $\alpha=(1-\eta)^{-1}$ and $\eta=\frac{\pi}{6}\left(\eta_{1} \sigma_{1}^{3}+\eta_{2} \sigma_{2}^{3}\right)$ is the packing fraction. is the atomic volume of an alloy for given concentration $\mathrm{C}_{1}$ and $\mathrm{C}_{2},\left(\mathrm{C}_{1}+\mathrm{C}_{2}=1\right) \cdot \mathrm{m}_{1}$ and $\mathrm{m}_{2}$ are atomic masses of the constituent species $n_{1}\left(=c_{1} / \quad\right)$ and $n_{2}\left(=c_{2} / \quad\right)$ are partial number densities. $K_{B}$ is the Boltzmann Constant.In Eq. (5),

$A=[\alpha(\alpha-1)-\operatorname{Pn} \alpha]\left(y_{1}+y_{2}\right)+3(\alpha-1) y_{1}$

where

$$
\mathrm{y}_{1}=\left(\sigma_{1}+\sigma_{2}\right) \sigma^{-3}
$$




$$
\mathrm{y}_{2}=\sigma_{1} \sigma_{2}\left(\mathrm{C}_{1} \sigma_{1}+\mathrm{C}_{2} \sigma_{2}\right) \sigma^{-6}
$$

where $\sigma=\left(C_{1} \sigma_{1}^{3}+C_{2} \sigma_{2}^{3}\right)^{1 / 3}$ is the hard-sphere diameter of the alloy. Following Eq.(1), the entropy of mixing for a binary alloy can be written as.

$$
\Delta S^{M}=\Delta S_{\text {gas }}+\Delta S_{\eta}+S_{\sigma}+S_{c}
$$

with

$$
\begin{gathered}
\Delta S_{\text {gas }}=S_{\text {gas }}^{\text {alloy }}-C_{1} S_{\text {gas }}^{(1)}-C_{2} S_{\text {gas }}^{(2)} \\
\Delta S_{\eta}=S_{\eta}^{\text {alloy }}-C_{1} S_{\eta}^{(1)}-C_{2} S_{\eta}^{(2)}
\end{gathered}
$$

Superscript 1 and 2 in Eqs. (10) and (11) refer to pure species 1 and 2 respectively. It is clear that for a given composition and volume of alloy, the entropy expressions contain two unknown parameters namely, hard sphere diameter $\sigma_{1}$ and $\sigma_{2}$. The packing fraction $\eta$ is easily derivable from the value of $\sigma$. In order to evaluate the value of $\sigma$ at different temperatures, we reduce the expression (2) to (5) to pure elements. For the corresponding pure liquid metals, we merely use $\mathrm{C}_{1}=1, \mathrm{C}_{2}=0$ and $\mathrm{C}_{2}=1, \mathrm{C}_{1}=0$ above.

The formalism is much simplified and, in particular, $S_{c}=0$ and $S_{\sigma}=0$ in Eq.(1). Thus

$$
S^{i}=S_{\text {gas }}^{i}-S_{\eta}^{i} \quad(i=1,2)
$$

with

$$
\begin{aligned}
& \frac{S^{i}}{K_{B}}=\frac{5}{2}+\ell_{n}\left\{\Omega_{i}\left(\frac{m^{i} K_{B} T}{2 \pi \hbar^{2}}\right)^{3 / 2}\right\} \\
& \frac{S^{i}}{K_{B}}=\ell_{n}\left(1-\eta_{i}\right)+\left\{1-\left(1-\eta_{i}\right)^{-2}\right\}
\end{aligned}
$$

where $\eta_{i}\left(=\frac{2 \pi \hbar^{2}}{\Omega_{i}}\right)$ is the packing fraction of pure liquid materials.

It may be mentioned that the well-known Carnahan and Starling [18-22] formula for the entropy of pure element can be obtained from Eq. (14) by expanding In $\left(1-\eta_{\mathrm{i}}\right)$ and retaining only the terms up to $\eta_{i}^{2}$. The packing fraction and hence the hard sphere the hence the hard sphere diameter has been determind at a given temperature by using Eq. (12) and taking the observed values of entropy from Hultgren et. al., The appropriate density of liquid metals required at a given temperature have been taken from literature [8]. 


\section{Results and Discussion}

In Table 1 . We have listed the computed values of $\sigma$ and $\eta$ for $\mathrm{Na}, \mathrm{K}, \mathrm{Rb}$ and $\mathrm{Cs}$ at temperatures $400^{\circ} \mathrm{K}$, $500^{\circ} \mathrm{K}, 600^{\circ} \mathrm{K}, 700^{\circ} \mathrm{K}$ and $800^{\circ} \mathrm{K}$ along with the available experimental values of entropy and density. The result shows that the values of $\eta$ vary from metal to metal. The maximum value is obtained for $\mathrm{Na}$ and the minimum value is for Cs. The values of $\eta$ also depend on temperature. As the temperature increases, $\eta$ decreases. The values of $(\mathrm{d} \eta / \mathrm{dT})$ for different alkali metals are of the order of:

$(\mathrm{d \eta} / \mathrm{dt})_{\mathrm{Na}}=-2.4^{*} 10^{-4}\left({ }^{\circ} \mathrm{K}\right)^{-1},(\mathrm{d \eta} / \mathrm{dt})_{\mathrm{k}}=-2.7^{*} 10^{-4}\left({ }^{\circ} \mathrm{K}\right)^{-1},(\mathrm{~d} \eta / \mathrm{dt})_{\mathrm{Rb}}=-2.9^{*} 10^{-4}\left({ }^{\circ} \mathrm{K}\right)^{-1}$ and $(\mathrm{d \eta} / \mathrm{dt})_{\mathrm{Cs}}=-2.9^{*} 10^{-}$ ${ }^{4}\left({ }^{\circ} \mathrm{K}\right)^{-1}$.

Though, these coefficients are very small, but they may affect the properties which are sensitive to temperature. The entropies of the pure alkali metals, $S$, are determind by adding ideal gas term $\left(S_{\mathrm{gas}}\right)$ and the packing density term $S_{\eta}$ through Eq. (12). The former is two to four times greater in magnitude and opposite in sign to $s_{\eta}$ for all the metals under consideration. The basic parameters required in the calculation are taken from Table 1.

Hard sphere parameters for pure elements as reported in Table 1, have also been utilised to compute the various contribution i.e. $S_{\text {gas }}, S_{c}, S_{\eta}$ and $S_{\eta}$ and $S_{\sigma}$ respectively from Eqs. (2) to (5) for alloys of interest. The relevant data for the various contribution to the entropy for alloys are listed in Tables 2 to 7 and hence $S^{\mathrm{M}}$ can easily be evaluated through Eq. (9) for these systems.

The computation of the various contribution to entropy are very important to understand the gross behaviour of alkali-alkali alloys. First we note that the absolute value of $\left|S_{\text {gas }}\right|$ are much larger than $\left|S_{\eta}\right|$ but after alloying $S_{\eta}$ becomes effective in comparison to $S_{\text {gas. }}$. This shows that in alloying the packing of constituent atoms are more important than the behaviour of individual atom in a given volume element. For investigating the effect of temperature on $\mathrm{S}^{\mathrm{M}}$ for all the six systems, the values of entropy of mixing are displayed in Figs. (1) to (6). A perusal of Figs: (1) to (3) reveals that $\mathrm{S}^{\mathrm{M}}$ of $\mathrm{Na}-\mathrm{K}, \mathrm{Na}-\mathrm{Rb}$ and $\mathrm{K}-\mathrm{Rb}$ alloys decreases with increasing temperature. But the result of $\mathrm{Na}-\mathrm{Cs}, \mathrm{Rb}-\mathrm{Cs}$ and $\mathrm{K}-\mathrm{Cs}$ systems exhibit a mixed behaviour. Near the melting point i.e. between $400^{\circ} \mathrm{K}$ to $600^{\circ} \mathrm{K}$ for Na-Cs $\mathrm{S}^{\mathrm{M}}$ increases with increasing temperature and above $600^{\circ} \mathrm{K}$ it starts falling towards the ideal entropy of mixing. But, $S^{\mathrm{M}}$ for $\mathrm{Rb}-\mathrm{Cs}$ and K-Cs alloys, increases with increasing temperature between $400^{\circ}$ to $500^{\circ}$ and above $500^{\circ} \mathrm{K}$ it starts falling similarly to Na-Cs.

Though the experimental values of temperature dependence of $S^{\mathrm{M}}$ for the above mentioned systems are not available in literature for an effective comparison, yet good accord with experiment for $\mathrm{Na}-\mathrm{K}$ and $\mathrm{Na}$ Cs at melting point confirms the validity of results obtained for these system at different temperatures.

Thus, our work provides an additional confidence in the hard sphere formalism for calculating the entropies of liquid metals and alloys. This is the most valuable contribution of semi-empirical approach to study $S^{M}$ of alkali-alkali alloys as a function of concentration and temperature. This is not easily accessible from any other source and such investigation to the best of our knowledge are completely lacking. 
In conclusion it may be asserted that this paper outlines the general theory of $\mathrm{S}^{\mathrm{M}}$ and the numerical values obtained for alloys form a good set of reliable data.

Table 1: The hard sphere parameters $(\sigma \eta)$ entropy $\left(S / K_{B}\right)$ and density of liquid alkali metals at different temperatures.

\begin{tabular}{|c|c|c|c|c|c|}
\hline \multirow{2}{*}{$\begin{array}{c}\text { Pure liquid } \\
\text { Metals }\end{array}$} & \multirow[b]{2}{*}{$\begin{array}{c}\text { Temp. } \\
\left({ }^{\circ} \mathbf{K}\right)\end{array}$} & \multicolumn{2}{|c|}{ Hard-Sphere parameter } & \multirow[b]{2}{*}{$\begin{array}{c}\text { Entropy } \\
\left(\mathbf{S} / \mathbf{K}_{\mathrm{B}}\right) \text { expt. }\end{array}$} & \multirow[b]{2}{*}{$\begin{array}{c}\text { Density (a.u) } \\
\text { expt. }\end{array}$} \\
\hline & & $\begin{array}{l}\text { Hard-sphere } \\
\text { diameter }(\sigma)\end{array}$ & Packing factor $(\eta)$ & & \\
\hline \multirow{5}{*}{ Sodium } & 400 & 6.052 & 0.4143 & 8.061 & 0.92038 \\
\hline & 500 & 5.954 & 0.3835 & 8.895 & 0.89438 \\
\hline & 600 & 5.872 & 0.3572 & 9.557 & 0.86838 \\
\hline & 700 & 5.804 & 0.3346 & 10.103 & 0.83238 \\
\hline & 800 & 5.725 & 0.3111 & 10.606 & 0.81638 \\
\hline \multirow{5}{*}{ Potassium } & 400 & 7.460 & 0.4027 & 9.724 & 0.812155 \\
\hline & 500 & 7.330 & 0.3710 & 10.556 & 0.788655 \\
\hline & 600 & 7.216 & 0.3434 & 11.226 & 0.765155 \\
\hline & 700 & 7.118 & 0.3194 & 11.782 & 0.741655 \\
\hline & 800 & 7.030 & 0.2980 & 12.261 & 0.718155 \\
\hline \multirow{5}{*}{ Rubidium } & 400 & 7.919 & 0.3928 & 11.259 & 1.447653 \\
\hline & 500 & 7.760 & 0.3578 & 12.119 & 1.401553 \\
\hline & 600 & 7.628 & 0.3287 & 12.796 & 1.355453 \\
\hline & 700 & 7.519 & 0.3041 & 13.351 & 1.309353 \\
\hline & 800 & 7.432 & 0.2833 & 13.821 & 1.263253 \\
\hline \multirow{5}{*}{ Caesium } & 400 & 8.416 & 0.3725 & 12.452 & 1.77885 \\
\hline & 500 & 8.185 & 0.3322 & 13.340 & 1.72385 \\
\hline & 600 & 8.042 & 0.3049 & 13.969 & 1.6685 \\
\hline & 700 & 7.954 & 0.2853 & 14.460 & 1.61385 \\
\hline & 800 & 7.886 & 0.2686 & 14.884 & 1.55885 \\
\hline
\end{tabular}


B.K. Singh et al./ BIBECHANA 14 (2017) 16-29 : RCOST p.21 (Online Publication: Dec., 2016)

Table 2 : Relevant data for $S_{\text {gas }} / K_{B}, S_{\mathfrak{\eta}} / K_{B}$ and $S_{0} / K_{B}$ used in the calculation.

\begin{tabular}{|c|c|c|c|c|c|}
\hline Alloys & $\operatorname{Temp}\left({ }^{\circ} \mathbf{K}\right)$ & $\mathrm{C}_{\mathrm{na}}$ & $\mathbf{S}_{\mathrm{gas}} / \mathbf{K}_{\mathrm{B}}$ & $-S_{\eta} / K_{B}$ & $\mathbf{S} / \mathbf{K}_{\mathbf{B}}$ \\
\hline \multirow{25}{*}{$\mathrm{Na}-\mathrm{K}$} & \multirow{5}{*}{400} & 0.8 & 11.6540 & 3.3480 & 0.0520 \\
\hline & & 0.7017 & 11.8033 & 3.3445 & 0.0632 \\
\hline & & 0.5001 & 12.1004 & 3.3064 & 0.0650 \\
\hline & & 0.2997 & 12.3844 & 3.2459 & 0.0475 \\
\hline & & 0.1999 & 12.5214 & 3.2153 & 0.0339 \\
\hline & \multirow{5}{*}{500} & 0.8 & 12.0158 & 2.8909 & 0.0434 \\
\hline & & 0.7017 & 12.1649 & 2.8862 & 0.0523 \\
\hline & & 0.5001 & 12.4624 & 2.8477 & 0.0542 \\
\hline & & 0.2997 & 12.7471 & 2.7914 & 0.0396 \\
\hline & & 0.1999 & 12.8842 & 2.7647 & 0.0283 \\
\hline & \multirow{5}{*}{600} & 0.8 & 12.3171 & 2.5463 & 0.0369 \\
\hline & & 0.7017 & 12.4659 & 2.5406 & 0.0449 \\
\hline & & 0.5001 & 12.7639 & 2.5015 & 0.0461 \\
\hline & & 0.2997 & 13.0494 & 2.4478 & 0.0336 \\
\hline & & 0.1999 & 13.1866 & 2.4237 & 0.0240 \\
\hline & \multirow{5}{*}{700} & 0.8 & 12.5769 & 2.2765 & 0.0318 \\
\hline & & 0.7017 & 12.7255 & 2.2697 & 0.0387 \\
\hline & & 0.5001 & 13.0240 & 2.2294 & 0.0398 \\
\hline & & 0.2997 & 13.3103 & 2.1770 & 0.0289 \\
\hline & & 0.1999 & 13.4476 & 2.1546 & 0.0207 \\
\hline & \multirow{5}{*}{800} & 0.8 & 12.8066 & 2.0320 & 0.0284 \\
\hline & & 0.7017 & 13.0347 & 2.0281 & 0.0326 \\
\hline & & 0.5001 & 13.2541 & 1.9951 & 0.0356 \\
\hline & & 0.2997 & 13.4632 & 1.9648 & 0.0289 \\
\hline & & 0.1999 & 13.6786 & 1.9307 & 0.0186 \\
\hline
\end{tabular}


Table 3: Relevant data for $S_{g a s} / K_{B}, S_{\eta} / K_{B}$ and $S_{g} / K_{B}$ used in the calculation.

\begin{tabular}{|c|c|c|c|c|c|}
\hline Alloys & $\operatorname{Temp}\left({ }^{\circ} \mathbf{K}\right)$ & $\mathrm{C}_{\mathrm{Rb}}$ & $\mathbf{S}_{\mathrm{gas}} / \mathbf{K}_{\mathrm{B}}$ & $-S_{\eta} / K_{B}$ & $S_{\sigma} / K_{B}$ \\
\hline \multirow{25}{*}{$\mathrm{Na}-\mathrm{Rb}$} & \multirow{5}{*}{400} & 0.2 & 13.649 & 3.036 & 0.04926 \\
\hline & & 0.3 & 13.385 & 3.054 & 0.06952 \\
\hline & & 0.5 & 12.841 & 3.099 & 0.09743 \\
\hline & & 0.7 & 12.270 & 3.163 & 0.09944 \\
\hline & & 0.8 & 11.971 & 3.206 & 0.08489 \\
\hline & \multirow{5}{*}{500} & 0.2 & 14.016 & 2.570 & 0.03864 \\
\hline & & 0.3 & 13.751 & 2.589 & 0.0563 \\
\hline & & 0.5 & 13.207 & 2.636 & 0.0789 \\
\hline & & 0.7 & 12.635 & 2.702 & 0.0808 \\
\hline & & 0.8 & 12.336 & 2.746 & 0.0690 \\
\hline & \multirow{5}{*}{600} & 0.2 & 14.322 & 2.229 & 0.0347 \\
\hline & & 0.3 & 14.058 & 2.248 & 0.0471 \\
\hline & & 0.5 & 13.512 & 2.294 & 0.0661 \\
\hline & & 0.7 & 12.940 & 2.359 & 0.0676 \\
\hline & & 0.8 & 12.640 & 2.404 & 0.0578 \\
\hline & \multirow{5}{*}{700} & 0.2 & 14.588 & 1.968 & 0.0271 \\
\hline & & 0.3 & 14.323 & 1.987 & 0.0394 \\
\hline & & 0.5 & 13.777 & 2.031 & 0.0566 \\
\hline & & 0.7 & 13.204 & 2.059 & 0.0580 \\
\hline & & 0.8 & 12.903 & 2.138 & 0.0496 \\
\hline & \multirow{5}{*}{800} & 0.2 & 14.824 & 1.762 & 0.0256 \\
\hline & & 0.3 & 14.559 & 1.777 & 0.0342 \\
\hline & & 0.5 & 14.012 & 1.815 & 0.0472 \\
\hline & & 0.7 & 13.438 & 1.868 & 0.0519 \\
\hline & & 0.8 & 13.137 & 1.904 & 0.0444 \\
\hline
\end{tabular}


Table 4: Relevant data for $S_{\text {gas }} / K_{B}, S_{\eta} / K_{B}$ and $S_{g} / K_{B}$ used in the calculation.

\begin{tabular}{|c|c|c|c|c|c|}
\hline Alloys & $\operatorname{Temp}\left({ }^{\circ} \mathbf{K}\right)$ & $\mathrm{C}_{\mathrm{k}}$ & $\mathbf{S}_{\mathrm{gas}} / \mathbf{K}_{\mathrm{B}}$ & $\mathbf{S}_{\eta} / \mathbf{K}_{\mathbf{B}}$ & $\mathbf{S}_{\sigma} / \mathbf{K}_{\mathrm{B}}$ \\
\hline \multirow{25}{*}{$\mathrm{K}-\mathrm{Rb}$} & \multirow{5}{*}{400} & 0.2022 & 13.8886 & 3.0419 & 0.00307 \\
\hline & & 0.3998 & 13.6177 & 3.0711 & 0.00478 \\
\hline & & 0.5004 & 13.4793 & 3.0864 & 0.00510 \\
\hline & & 0.6005 & 13.3418 & 3.0980 & 0.00501 \\
\hline & & 0.8514 & 12.9946 & 3.1353 & 0.00281 \\
\hline & \multirow{5}{*}{500} & 0.2022 & 14.2519 & 2.5910 & 0.00236 \\
\hline & & 0.3998 & 13.9817 & 2.6177 & 0.00367 \\
\hline & & 0.5004 & 13.8431 & 2.6342 & 0.00392 \\
\hline & & 0.6005 & 13.7068 & 2.6415 & 0.01079 \\
\hline & & 0.8514 & 13.3579 & 2.6883 & 0.00216 \\
\hline & \multirow{5}{*}{600} & 0.2022 & 14.5549 & 2.2586 & 0.00191 \\
\hline & & 0.3998 & 14.2853 & 2.2817 & 0.00297 \\
\hline & & 0.5004 & 14.1465 & 2.2979 & 0.00317 \\
\hline & & 0.6005 & 14.0115 & 2.3011 & 0.00310 \\
\hline & & 0.8514 & 13.6610 & 2.3516 & 0.00175 \\
\hline & \multirow{5}{*}{700} & 0.2022 & 14.8166 & 2.0044 & 0.00163 \\
\hline & & 0.3998 & 14.5476 & 2.0229 & 0.00256 \\
\hline & & 0.5004 & 14.4086 & 2.0380 & 0.00271 \\
\hline & & 0.6005 & 14.2749 & 2.0369 & 0.00265 \\
\hline & & 0.8514 & 13.9227 & 2.0873 & 0.00149 \\
\hline & \multirow{5}{*}{800} & 0.2022 & 15.0483 & 1.8047 & 0.00148 \\
\hline & & 0.3998 & 14.7800 & 1.8177 & 0.00231 \\
\hline & & 0.5004 & 14.6408 & 1.8309 & 0.00246 \\
\hline & & 0.6005 & 14.5086 & 1.8254 & 0.00239 \\
\hline & & 0.8514 & 14.1544 & 1.8728 & 0.00136 \\
\hline
\end{tabular}


Table 5: Relevant data for $S_{g a s} / K_{B}, S_{\eta} / K_{B}$ and $S_{\sigma} / K_{B}$ used in the calculation.

\begin{tabular}{|c|c|c|c|c|c|}
\hline Alloys & $\operatorname{Temp}\left({ }^{\circ} \mathbf{K}\right)$ & $\mathrm{C}_{\mathrm{na}}$ & $\mathbf{S}_{\mathrm{gas}} / \mathbf{K}_{\mathrm{B}}$ & $\mathbf{S}_{\eta} / \mathbf{K}_{\mathbf{B}}$ & $\mathbf{S}_{\sigma} / \mathbf{K}_{\mathrm{B}}$ \\
\hline \multirow{25}{*}{$\mathrm{Na}-\mathrm{Cs}$} & \multirow{5}{*}{400} & 0.1518 & 14.5366 & 2.8643 & 0.0503 \\
\hline & & 0.3 & 14.0109 & 3.0122 & 0.0969 \\
\hline & & 0.5023 & 13.2769 & 3.1965 & 0.1470 \\
\hline & & 0.7014 & 12.5326 & 3.3140 & 0.1579 \\
\hline & & 0.8 & 12.1507 & 3.3468 & 0.1378 \\
\hline & \multirow{5}{*}{500} & 0.1578 & 14.9034 & 2.3469 & 0.0380 \\
\hline & & 0.3 & 14.3783 & 2.4667 & 0.0731 \\
\hline & & 0.5023 & 13.6410 & 2.6420 & 0.1113 \\
\hline & & 0.7014 & 12.8960 & 2.7679 & 0.1201 \\
\hline & & 0.8 & 12.5133 & 2.8206 & 0.1053 \\
\hline & \multirow{5}{*}{600} & 0.1518 & 15.2099 & 2.0384 & 0.0391 \\
\hline & & 0.3 & 14.6855 & 2.1377 & 0.0611 \\
\hline & & 0.5023 & 13.9448 & 2.3007 & 0.0933 \\
\hline & & 0.7014 & 13.1990 & 2.4167 & 0.1006 \\
\hline & & 0.8 & 12.8115 & 2.4703 & 0.0884 \\
\hline & \multirow{5}{*}{700} & 0.1518 & 15.4754 & 1.8332 & 0.0285 \\
\hline & & 0.3 & 14.9517 & 1.9164 & 0.0543 \\
\hline & & 0.5023 & 14.2072 & 2.0680 & 0.0832 \\
\hline & & 0.7014 & 13.4607 & 2.1692 & 0.0896 \\
\hline & & 0.8 & 13.0763 & 2.2176 & 0.0787 \\
\hline & \multirow{5}{*}{800} & 0.1578 & 15.7112 & 1.6674 & 0.0263 \\
\hline & & 0.3 & 15.1882 & 1.7355 & 0.0501 \\
\hline & & 0.5023 & 14.4397 & 1.8732 & 0.0768 \\
\hline & & 0.7014 & 13.6923 & 1.9547 & 0.0825 \\
\hline & & 0.8 & 13.3070 & 1.9932 & 0.0724 \\
\hline
\end{tabular}


Table 6: Relevant data for $S_{g a s} / K_{B}, S_{\eta} / K_{B}$ and $S_{0} / K_{B}$ used in the calculation.

\begin{tabular}{|c|c|c|c|c|c|}
\hline Alloys & $\operatorname{Temp}\left({ }^{\circ} \mathbf{K}\right)$ & $\mathbf{C}_{\mathbf{R b}}$ & $\mathbf{S}_{\mathrm{gas}} / \mathbf{K}_{\mathrm{B}}$ & $\mathbf{S}_{\eta} / \mathbf{K}_{\mathbf{B}}$ & $\mathbf{S}_{\sigma} / \mathbf{K}_{\mathrm{B}}$ \\
\hline \multirow{25}{*}{$\mathrm{Rb}-\mathrm{Cs}$} & \multirow{5}{*}{400} & 0.2 & 14.888 & 2.775 & 0.0028 \\
\hline & & 0.3 & 14.799 & 2.795 & 0.0038 \\
\hline & & 0.5 & 14.621 & 2.848 & 0.0048 \\
\hline & & 0.7 & 14.441 & 2.906 & 0.0043 \\
\hline & & 0.8 & 14.350 & 2.936 & 0.0032 \\
\hline & \multirow{5}{*}{500} & 0.2 & 15.254 & 2.285 & 0.00177 \\
\hline & & 0.3 & 15.166 & 2.311 & 0.00232 \\
\hline & & 0.5 & 14.988 & 2.367 & 0.00303 \\
\hline & & 0.7 & 14.808 & 2.429 & 0.00271 \\
\hline & & 0.8 & 14.717 & 2.464 & 0.00213 \\
\hline & \multirow{5}{*}{600} & 0.2 & 15.560 & 1.987 & 0.0015 \\
\hline & & 0.3 & 15.472 & 2.009 & 0.0021 \\
\hline & & 0.5 & 15.294 & 2.056 & 0.0025 \\
\hline & & 0.7 & 15.114 & 2.108 & 0.0023 \\
\hline & & 0.8 & 15.023 & 2.137 & 0.0018 \\
\hline & \multirow{5}{*}{700} & 0.2 & 15.825 & 1.785 & 0.00149 \\
\hline & & 0.3 & 15.737 & 1.802 & 0.00201 \\
\hline & & 0.5 & 15.559 & 1.836 & 0.00253 \\
\hline & & 0.7 & 15.379 & 1.874 & 0.00225 \\
\hline & & 0.8 & 15.289 & 1.894 & 0.00169 \\
\hline & \multirow{5}{*}{800} & 0.2 & 16.061 & 1.626 & 0.00149 \\
\hline & & 0.3 & 15.973 & 1.637 & 0.00201 \\
\hline & & 0.5 & 15.795 & 1.662 & 0.00252 \\
\hline & & 0.7 & 15.615 & 1.689 & 0.00225 \\
\hline & & 0.8 & 15.525 & 1.705 & 0.00176 \\
\hline
\end{tabular}


B.K. Singh et al./ BIBECHANA 14 (2017) 16-29 : RCOST p.26 (Online Publication: Dec., 2016)

Table 7. Relevant data for $S_{g a s} / K_{B}, S_{\eta} / K_{B}$ and $S_{0} / K_{B}$ used in the calculation.

\begin{tabular}{|c|c|c|c|c|c|}
\hline Alloys & $\operatorname{Temp}\left({ }^{\circ} \mathbf{K}\right)$ & $\mathrm{C}_{\mathrm{k}}$ & $\mathbf{S}_{\mathrm{gas}} / \mathbf{K}_{\mathrm{B}}$ & $\mathbf{S}_{\eta} / \mathbf{K}_{\mathrm{B}}$ & $S_{\sigma} / K_{B}$ \\
\hline \multirow{25}{*}{$\mathrm{K}-\mathrm{Cs}$} & \multirow{5}{*}{400} & 0.2 & 14.632 & 2.783 & 0.0106 \\
\hline & & 0.3 & 14.400 & 2.815 & 0.0105 \\
\hline & & 0.5 & 13.951 & 2.887 & 0.0191 \\
\hline & & 0.7 & 13.493 & 2.975 & 0.0179 \\
\hline & & 0.8 & 13.261 & 3.027 & 0.0145 \\
\hline & \multirow{5}{*}{500} & 0.2 & 14.988 & 2.298 & 0.00721 \\
\hline & & 0.3 & 14.766 & 2.333 & 0.00993 \\
\hline & & 0.5 & 14.315 & 2.413 & 0.01311 \\
\hline & & 0.7 & 13.857 & 2.511 & 0.01234 \\
\hline & & 0.8 & 13.625 & 2.568 & 0.01001 \\
\hline & \multirow{5}{*}{600} & 0.2 & 15.294 & 2.002 & 0.00598 \\
\hline & & 0.3 & 15.071 & 2.032 & 0.00822 \\
\hline & & 0.5 & 14.620 & 2.104 & 0.01085 \\
\hline & & 0.7 & 14.162 & 2.191 & 0.01021 \\
\hline & & 0.8 & 13.929 & 2.242 & 0.00827 \\
\hline & \multirow{5}{*}{700} & 0.2 & 15.558 & 1.801 & 0.00557 \\
\hline & & 0.3 & 15.335 & 1.827 & 0.00767 \\
\hline & & 0.5 & 14.884 & 1.884 & 0.01009 \\
\hline & & 0.7 & 14.425 & 1.955 & 0.00950 \\
\hline & & 0.8 & 14.193 & 1.997 & 0.00766 \\
\hline & \multirow{5}{*}{800} & 0.2 & 15.793 & 1.640 & 0.00536 \\
\hline & & 0.3 & 15.570 & 1.660 & 0.00736 \\
\hline & & 0.5 & 15.118 & 1.708 & 0.00967 \\
\hline & & 0.7 & 14.659 & 1.765 & 0.01552 \\
\hline & & 0.8 & 14.426 & 1.799 & 0.00732 \\
\hline
\end{tabular}




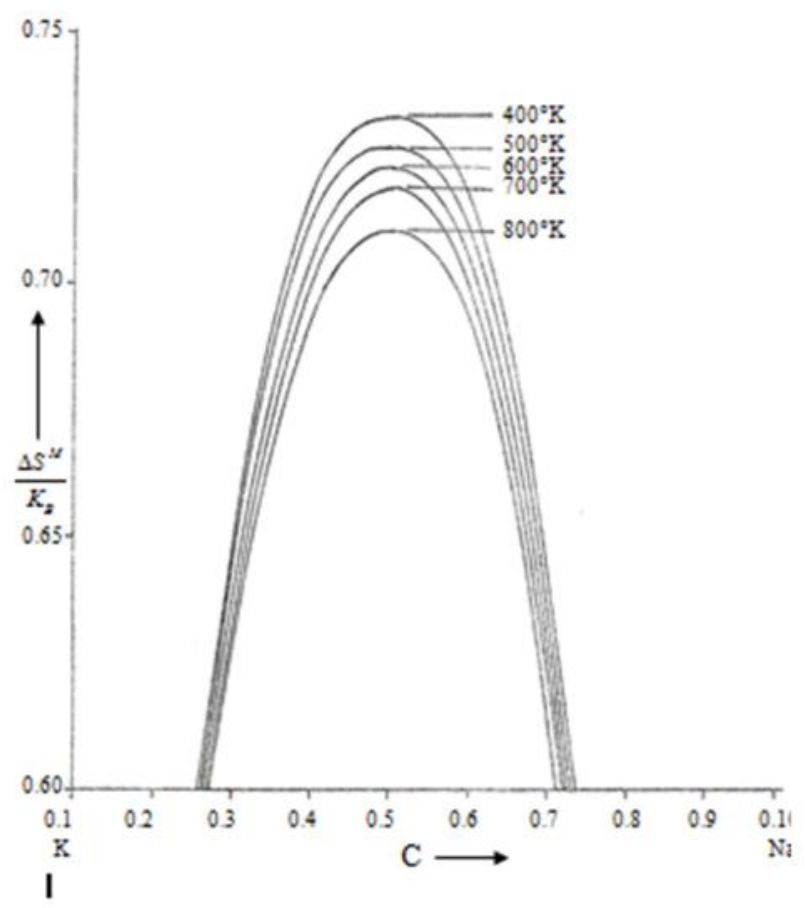

Fig. 1: Entropy of mixing $\left(\Delta S^{M} / K_{B}\right)$ of $N a-K$ as $\mathrm{a}$ as a function of concentration and temperature.

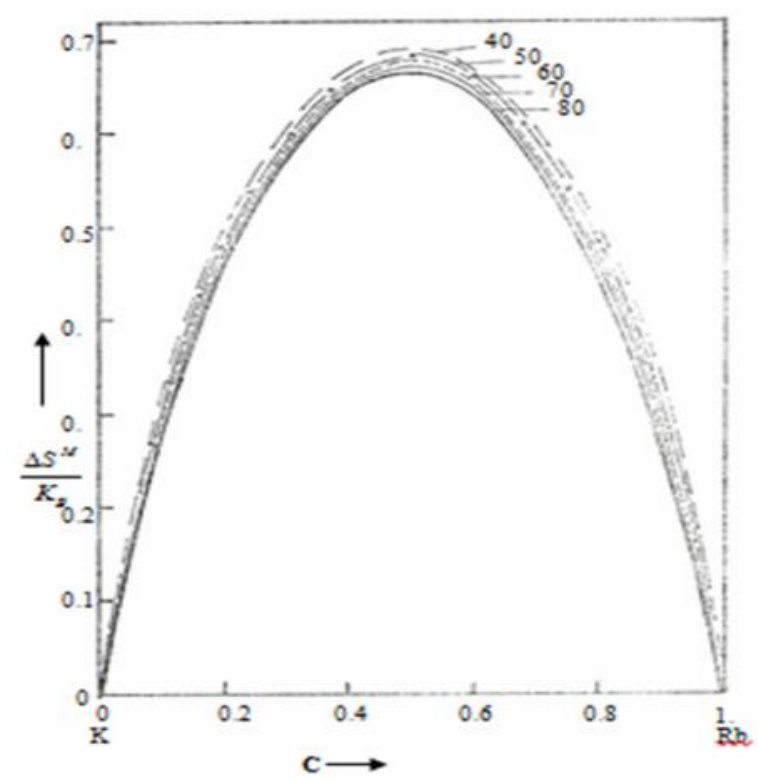

Fig. 3: Temperature dependence of the entropy of mixing $\left(\Delta \mathrm{S}^{\mathrm{M}} / \mathrm{K}_{\mathrm{B}}\right)$ for liquid $\mathrm{K}-\mathrm{Rb}$ alloys.

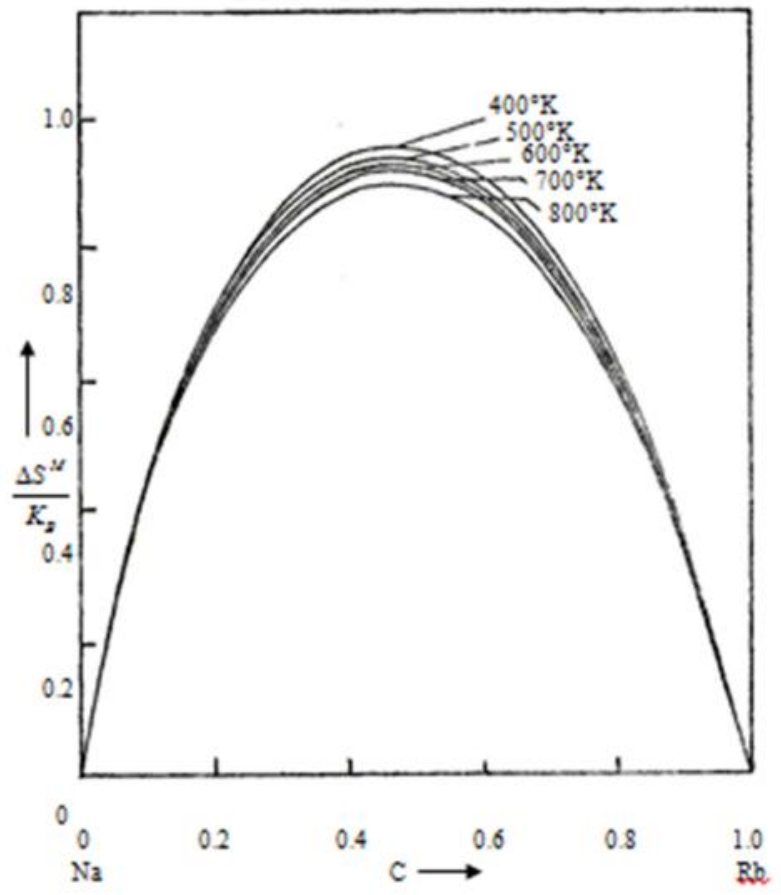

Fig. 2: Entropy of mixing of $\left(\Delta S^{\mathrm{M}} / \mathrm{K}_{\mathrm{B}}\right) \mathrm{Na}-\mathrm{Rb}$ alloys function of concentration and temperature.

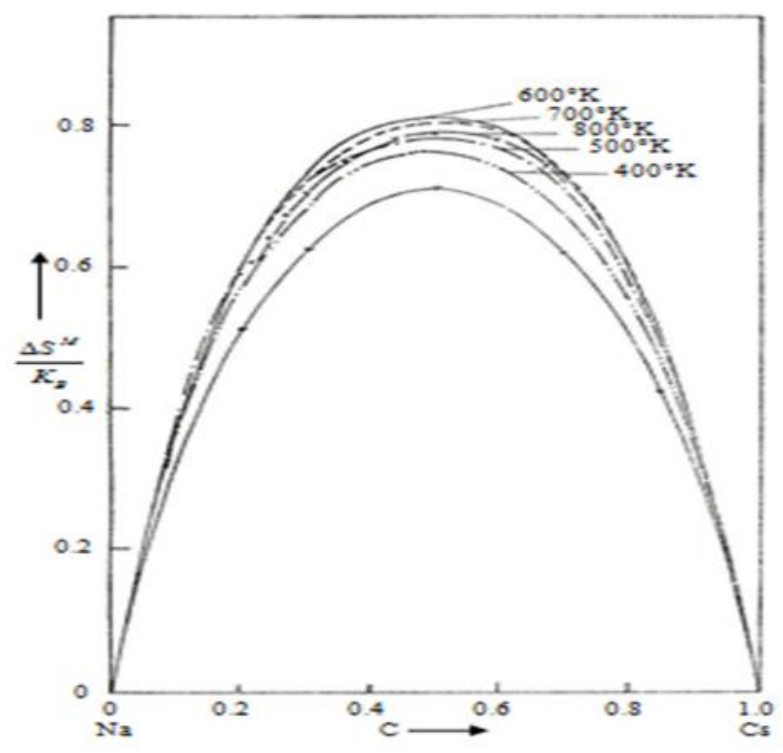

Fig. 4: Temperature dependence of the entropy of mixing $\left(\Delta \mathrm{S}^{\mathrm{M}} / \mathrm{K}_{\mathrm{B}}\right)$ for liquid Na-Cs alloys. corresponds to the experimental value at $380^{\circ} \mathrm{K}$ of Neale \& Caoack (1982). 


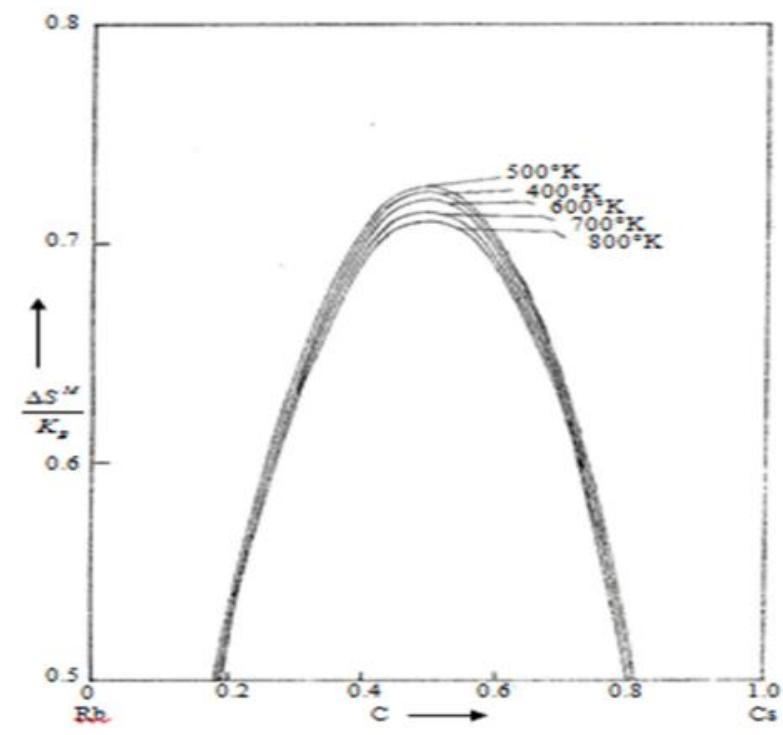

Fig. : Entropy of mixing $\left(\Delta \mathrm{S}^{\mathrm{M}} / \mathrm{K}_{\mathrm{B}}\right)$ of $(\mathrm{Rb}-\mathrm{Cs})$ alloys as a function of Temperature.

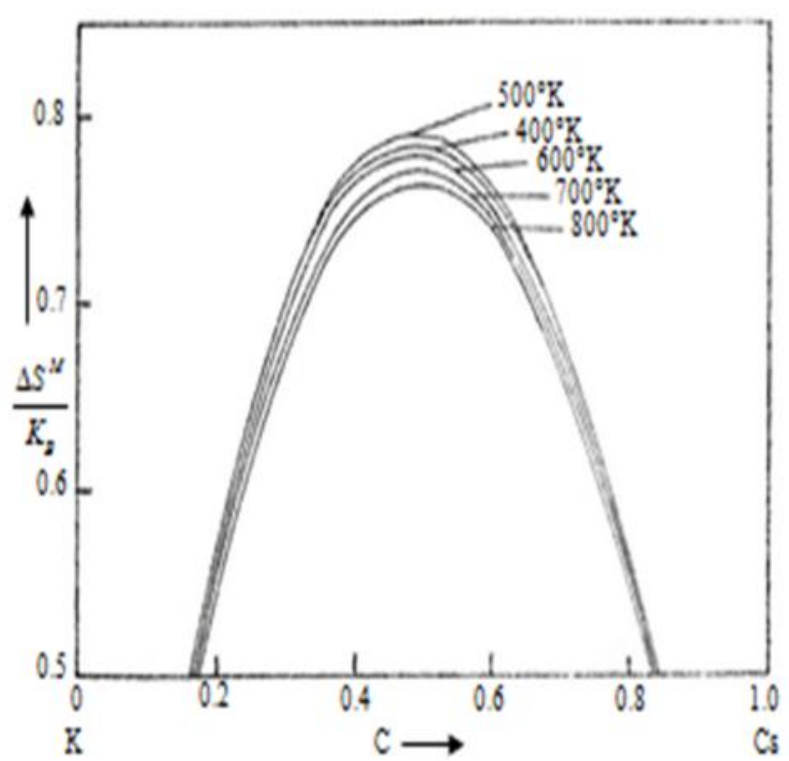

Fig. 6: Entropy of mixing $\left(\Delta \mathrm{S}^{\mathrm{M}} / \mathrm{K}_{\mathrm{B}}\right)$ for liquid (K-Cs) alloys as a function of temperature \& concentration.

\section{References}

[1] R. Hultgren, P.D. Desai, M. Glesier, K.K Kelley, D.D Wagman, Selected values of the thermodynamic properties of the elements and binary alloys. Vol. I \& II (1973), American Society of Metals, Ohio.

[2] I.H. Umar, A. Mayer, M. Watable , \& W.H. Young, J. Phys. F : Metal Phys., 4 (1974) 1691. http://dx.doi.org/10.1088/0305-4608/4/10/016

[3] Hafner, J. Phys. Rev. A 16 (1977) 351. http://dx.doi.org/10.1103/PhysRevA.16.351

[4] R.N. Singh \& S. Singh, Physica, 128 B (1985)304.

[5] B. Karaoglu \& W.H. Young, J. phys.: Condens, Matter, 2 (1990)S 189-9197.

[6] M. Shimoji, Liquid Metals (Academic press London) (1977).

[7] I. Yokoyama, A. Meyer, M.J. Stott and W.H.Young, Phil. Mag., 35 (1973) 1021. http://dx.doi.org/10.1080/14786437708232642

[8] M. J. Huijben, Ph.D. Thesis (1978), University of Groningen, The Netherlands.

[9] A.B. Bhatia and N.H. March, J, Phy. F : Metal Phys., 5 (1975)1100. http://dx.doi.org/10.1088/0305-4608/5/6/011

[10] E.G. Visser, L.W. Vander L and J. Th. M. de Hosson, J. Phys. F: Metal Phys., 10 (1980) 1681. http://dx.doi.org/10.1088/0305-4608/10/8/008

[11] R.N. Singh and A.B. Bhatia, J. Phys. F : Metal Phys., 14 (1984) 2309. http://dx.doi.org/10.1088/0305-4608/14/10/009 
[12] F.E. Neale and J. Cusack, Non-Cryst. Solids, 61-62 (1984) 169.

[13] K. Ichikawa, S. M. Granstaff and J.C. Thompson , J. Chem. Phys, 61(1974) 4069. http://dx.doi.org/10.1063/1.1681699

[14] M.J. Huijben, L.W. Varder ., A. M. Hosson, J. Th. M. Cle Reimert, and C. Van Dijk, Physica, 97B (1979) 338.

[15] F.E. Neale and J. Cusack, J. Phys. F: Metal Phys., 12 (1982) 2839. http://dx.doi.org/10.1088/0305-4608/12/12/016

[16] I.H. Umar, I. Yokoyama and W.H. Young, Phil. Mag., 34 (1976) 535. http://dx.doi.org/10.1080/14786437608223792

[17] G.A. Mansoori , N.F. Crnahan, K.E. Starling and T.W. Leland, J. Chem. Phys., 54(1971) 1523. http://dx.doi.org/10.1063/1.1675048

[18] N.F. Carnahan and K.E. Starling, J. Chem. Phys., 51(1969) 635. http://dx.doi.org/10.1063/1.1672048

[19] D. Adhikari, B.P. Singh, I .S. Jha, B.K. Singh, J. Non-crystalline solids, 357 (2011) 2892. http://dx.doi.org/10.1016/j.jnoncrysol.2011.03.029

[20] D. Adhikari, I.S. Jha, B.P. Singh , Phil. Mag., 90 (2010) 2687. http://dx.doi.org/10.1080/14786431003745302

[21] D. Adhikari, B.P. Singh, I.S. Jha, B.K. Singh , J. Mol. Liq., 156 (2010) 115-119. http://dx.doi.org/10.1016/j.molliq.2010.05.020 